\title{
LA OCUPACIÓN DE ÉPOCA VISIGODA EN VEGA DE DUERO (VILLABÁÑEZ, VALLADOLID)
}

POR

\author{
ANTONIO BELLIDO BLANCO \\ Universidad de Valladolid
}

\begin{abstract}
RESUMEN
El yacimiento de época visigoda de Vega Duero ha venido a proporcionar una de las primeras evidencias de hábitat dentro del valle medio del Duero, que rompe con el tradicional desconocimiento de estos contextos. Sus evidencias materiales manifiestan un bagaje cultural bien distinto del que deparan las numerosas necrópolis excavadas en la zona y marcan una importante referencia para la identificación de nuevos poblados sincrónicos.
\end{abstract}

\section{SUMMARY}

Vega Duero, a recently discovered site from Visigothic chronology, provides one of the first examples of a context of habitat in the midvalley of the Duero River. The archaeological evidence shows a cultural equipment quite different from that recovered up to now from the many burying grounds excavated in the area, being thus a significant reference for identification of further contemporary settlements.

A mediados de diciembre de 1992 se iniciaba una pequeña excavación en el pago Vega Duero, dentro del término municipal de Villabáñez (Valladolid), en una zona próxima al cauce actual del río Duero y al pie del páramo del Cerrato. La intervención, programada dentro del Convenio de Arqueología 1992 (firmado por la Junta de Castilla y León, la Diputación de Valladolid y la Universidad de Valladolid), pretendía, mediante una serie de sondeos, definir la entidad del yacimiento y sus características.

El lugar se encuentra en la orilla derecha del río Duero (fig. 1) ${ }^{1}$, en el interior de uno de sus meandros, sobre un área donde las arcillas aluviales que componen el sustrato geológico han formado una extensión plana que mantiene una casi imperceptible pendiente hasta el arranque de la ladera del páramo, a tan sólo unos pocos cientos de metros hacia el norte. Las unidades de excavación se trazaron en torno a varias evidencias arqueológicas que la erosión había dejado al descubierto en el cortado que

1 Los dibujos de materiales son obra de Ángel Rodríguez González; las planimetrías, del autor. el terreno formaba junto al río. Conforme a los objetivos propuestos, los trabajos arqueológicos se limitaron a cuatro catas independientes que, siguiendo la línea del cortado, coincidían con puntos donde se apreciaban alteraciones antrópicas dentro de la continuidad del sustrato geológico. El resultado de los trabajos fue la identificación de dos ocupaciones en el pago bien individualizadas cultural y cronológicamente.

\section{LOS RESULTADOS DE LA EXCAVACIÓN}

La primera presencia humana detectada en Vega Duero, que no vamos a analizar aquí, se encuadra en un momento calcolítico y las estructuras identificadas se reducían a una fosa de considerables dimensiones, con $80 \mathrm{~cm}$ de profundidad y un diámetro cercano a $2,8 \mathrm{~m}$, de la que se recogieron varias piedras de molino, escasa industria lítica y distintos materiales cerámicos. Entre estos últimos destacaban ollas de borde recto o ligeramente reentrante, así como, dentro de la vajilla más fina, vasos globulares y cuencos hemisféricos. Del otro momento, correspondiente a época visigoda, fueron excavadas dos fosas más y parte de lo que parecía ser un área marginal del asentamiento. Ambas fosas se disponían bajo un estrato horizontal, cuya potencia oscilaba entre 60 y $16 \mathrm{~cm}$, que contenía restos similares a los encontrados en los hoyos, pero que carecía de estructuras y había sido revuelto en su zona más superficial por la acción del arado. Todos los estratos de este segundo momento de presencia humana en el lugar contenían en mayor o menor medida materiales calcolíticos, hecho que vendría determinado por la destrucción parcial de las estructuras anteriores y la intrusión fortuita de sus restos entre los niveles visigodos.

La cata dispuesta sobre lo que pareció ser una zona marginal del asentamiento no deparó estructura alguna y tan sólo un par de niveles, de dudoso origen antrópico, contenía algún material que adscribimos a la segunda fase de ocupación del pago. 

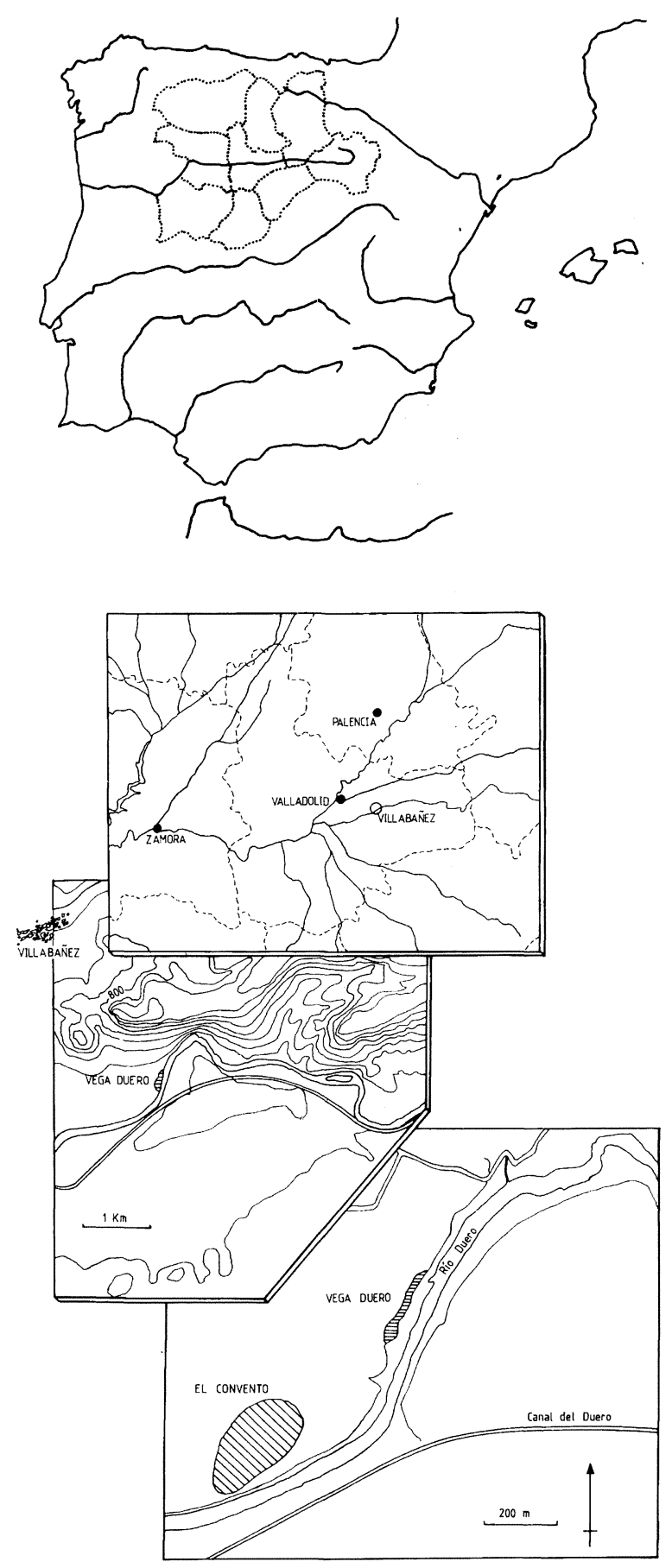

Fig. 1.-Localización del yacimiento Vega Duero (Villabáñez, Valladolid).

El primero de los pozos excavados (fig. 2) tenía $80 \mathrm{~cm}$ de profundidad y, aunque su extensión superaba los límites del área de excavación, sabemos que su diámetro era mayor de tres metros. El relle- no interior consistía en una tierra grisácea, rica en intrusiones de ceniza y algunos manchones de greda en la parte superior, dentro de la que aparecía un elevado número de huesos de fauna, además de abundantes cerámicas muy fragmentadas. Todos los materiales habían sido depositados de modo anárquico, salvo una pequeña concentración cerca de la base, cuyos restos principales eran un cuchillo, la mitad de unas tijeras y parte de una olla. Según su contenido parece tratarse de un nivel con desechos domésticos, y la presencia de mogotes de greda extraídos del suelo del entorno podría ser indicio de que todo el relleno responde a la intención de colmatar la fosa con rapidez. Las piezas agrupadas en el fondo serían el fruto de un primer vertido de basuras que, por su disposición y menor fragmentación, constituirían un depósito primario. Recogimos en esta fosa un par de fragmentos de terra sigillata.

El segundo hoyo resultó bastante distinto. Sus dimensiones eran de $60 \mathrm{~cm}$ de profundidad y unos 3,6 m de diámetro (fig. 2). La superficie del fondo era muy irregular y se encontraba rubefactada y endurecida por el fuego. El tramo conservado de las paredes del hoyo también estaba parcialmente endurecido y en él se apreciaban tres agujeros separados entre sí por una distancia de un metro. El relleno era ceniciento, con algunos carbones pequeños, y contenía fragmentos de teja curva junto a, ya en el fondo, piedras calizas de gran tamaño. Eran escasos los huesos pero abundaban las cerámicas y aparecieron también varias escorias que, unidas a la rubefacción del fondo, podrían dar alguna pista sobre la función original de la estructura en el momento en que sean analizadas. No cabe dudar, pese a la ausencia de datos más precisos, de que se trataría de algún tipo de horno.

Dejando de lado esta estructura, que resulta un poco atípica, fosas similares a la primera se han reconocido en número de treinta en el yacimiento madrileño de Perales, donde se han interpretado como basureros (Quero y Martín, 1987). Otras tres más se documentan en el Camino de los Afligidos (Alcalá de Henares) donde se consideran «basureros o vertederos de una villa agrícola» (Fernández-Galiano, 1976b: 46) y, de manera similar a Vega Duero, los materiales recogidos incluyen diversas vasijas casi enteras y varios objetos de hierro fragmentados, todo ello ya inútil cuando se arrojó (ibídem: 61) correspondiendo más a vertidos de desecho que a ocultaciones, como parece el hoyo de Getafe (Caballero, 1985: 98).

No obstante, para un hoyo del yacimiento medieval de Arguíroz (Navarra) se defiende que, pese a los residuos contenidos, habría servido para almace- 


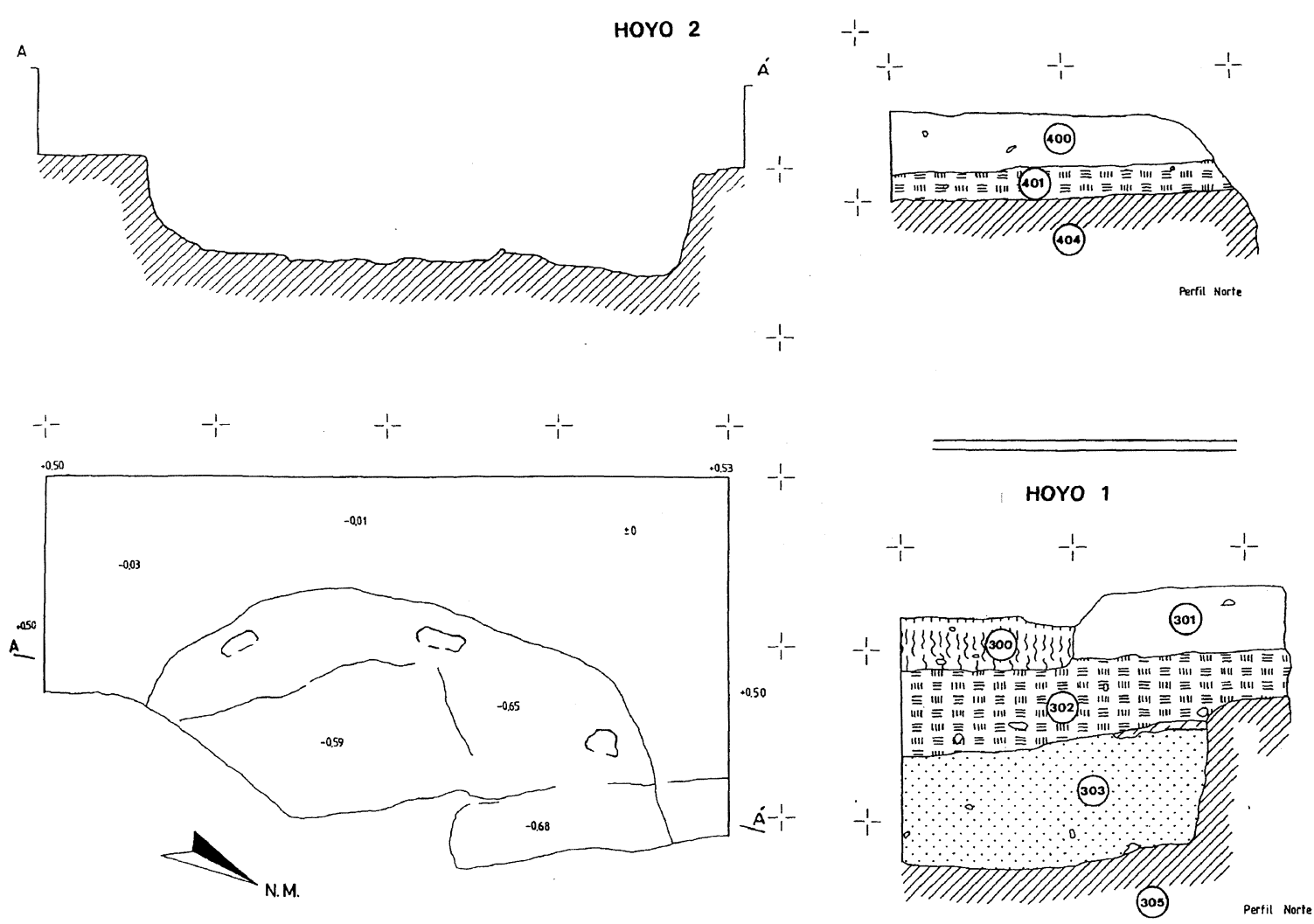

Fig. 2.-Planos de las estructuras de época visigoda. Planta y dos secciones del hoyo n. ${ }^{\circ} 2$, identificado como un posible horno; en el ángulo inferior derecho, una sección del hoyo n. ${ }^{\circ}$. Escala 1/50.

namiento de cereales u otros productos de consumo (Josué, 1988: 304), y la misma utilidad se ha inferido para las estructuras de Los Castellares (Herrera de los Navarros, Zaragoza; Burillo, 1983: 137).

$\mathrm{Si}$ acudimos al análisis de asentamientos medievales y modernos posteriores, se observa la existencia de un número destacado de fosas excavadas en el subsuelo que eran dedicadas a silos para guardar el grano y en ocasiones la paja. Su funcionalidad se documenta también en los textos romanos, pues Varón, en De Re Rustica, comenta que en Carthago Nova los silos normales eran los putei (I, 57, 2), unos hoyos cuyo fondo se recubría con paja para aislar el grano (Martínez y Matilla, 1988: 507). E incluso este sistema tradicional de almacenamiento se ha mantenido hasta hace pocos años en distintos puntos de Castilla y León, situándose los almacenes en la entrada de la casa, bajo el zaguán (Alonso Ponga, 1986: 48). De ello cabe sospechar la posibilidad de que el hoyo de Vega Duero hubiese servido en origen como silo; con más razón aún si se piensa que en comunidades agrícolas los desechos orgánicos constituyen un excelente abono para los campos y no tendría sentido la excavación de fosas para lograr su eliminación.

\section{LOS MATERIALES ARQUEOLÓGICOS}

La reducida entidad de la muestra material recogida impide establecer conjuntos coherentes independientes para cada una de las estructuras, por lo cual a efectos prácticos se considera toda la excavación como un solo conjunto. Los restos corresponden a desechos, factor determinante de que se presenten sumamente fragmentados y que ha influido en la ausencia de vasijas completas. Se observa el absoluto predominio de la cerámica, si bien no faltan los hallazgos faunísticos (sobre todo en el interior del silo-vertedero) y metálicos.

De las piezas metálicas (fig. 3), la primera que llama nuestra atención es un cuchillo de hierro con los bordes de la hoja casi paralelos, aunque el lado del filo se curva en el extremo distal para unirse al otro borde. El vástago para el mango, que conservaba algunos restos de madera, parte del centro de la 


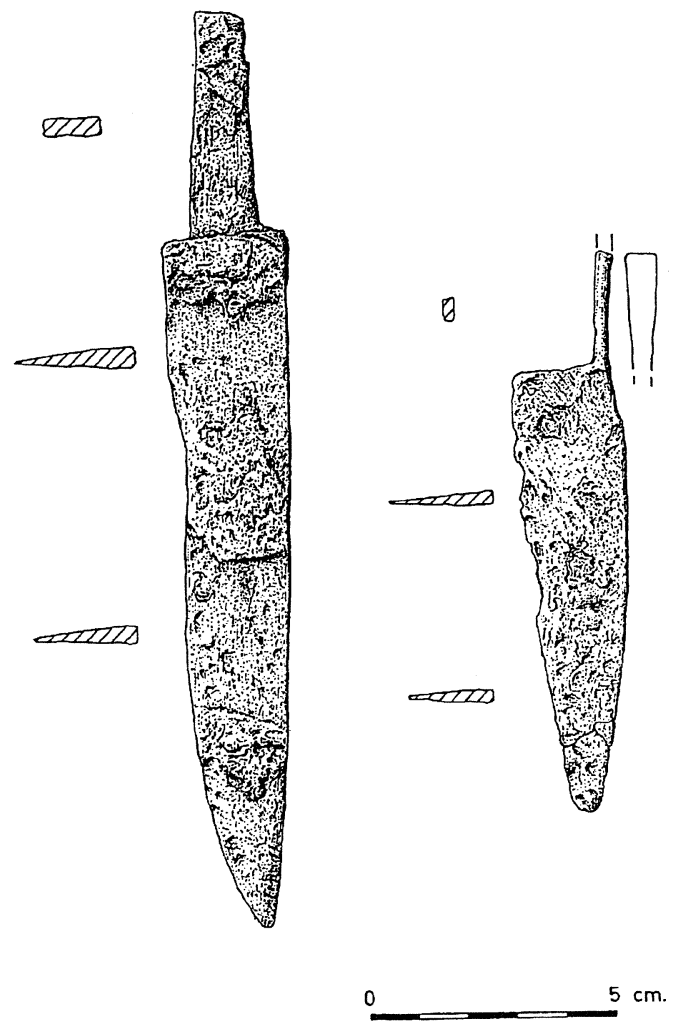

Fig. 3.-Piezas metálicas: cuchillo de hierro y fragmento de tijeras. Escala 1/2.

zona proximal de la hoja. Su tipología dista mucho de los cuchillos con funda tipo «Simancas» o del modelo afalcatado, pese a que ambos resultan los mejor conocidos o más prototípicos del periodo tardorromano (Palol, 1964; Caballero, 1974: 64-7).

Dentro del Castro de Yecla (Burgos) se encontraron dos puñales afalcatados cuyo modelo se incluye dentro de la tipología tardorromana (Caballero, 1974: 66), pero al mismo tiempo se recogió en la vivienda visigoda $B$, entre otros objetos, un cuchillo no demasiado distinto al de Vega Duero (González, 1947: 31 y lám. XXII, $n^{\circ} 3$ ). Otros puñales similares al nuestro se documentan en otros yacimientos visigodos, como el catalán de Fuente del Moro (Colmenarejo, 1986: 235) y en la necrópolis de El Carpio de Tajo (Toledo), concretamente dentro de las sepulturas 49, 149, 160 y 196 (Ripoll, 1985: 58-9; 1993-1994). En este último estudio se alude a la existencia de piezas semejantes en las necrópolis de Pamplona, Estagel, Daganzo de Arriba, Duratón y Herrera de Pisuerga (Zeiss, 1934).

También realizada en hierro, fue hallada una tijera (forfex) de la que se conserva una de las hojas triangulares y el arranque del pedúnculo, de sección rectangular. No menudean los paralelos de época visigoda, lo cual nos obliga a recurrir a modelos romanos. Con esta datación, las tijeras son de hojas triangulares y para los ejemplares en hierro predominan los vástagos de sección rectangular, al tiempo que la unión entre las dos hojas se hace siempre en horquilla (Borobia, 1988: 240, 270, 286), sistema que creemos el más probable para la pieza de Vega Duero, ya que los vástagos doblados sobre sí mismos se elaboran con sección circular mayoritariamente. Entre los yacimientos tardorromanos, en el enjundioso lote de materiales metálicos de la sepultura I de Fuentespreadas se incluía una tijera de hierro. Su morfología se define a partir de dos hojas triangulares y mango de sección rectangular con sistema de horquilla (Caballero, 1974: 122 y lám. IX). Otra pieza sincrónica muy parecida se recogió en el enterramiento de San Miguel del Arroyo (Valladolid; Palol, 1969).

Mientras que en tijeras de bronce no se duda de su empleo médico, incluso para intervenciones quirúrgicas (Celso, De Re Medica, Lib. VII, XVI), no existe la misma seguridad para atribuir una función a las de hierro (Borobia, 1988: 270 y 286), aunque se sostiene que eran usadas para cortar el pelo (ibídem: 26) y para esquilar ovejas y cortar telas (Manning, 1989: 34).

La presencia de estos materiales metálicos entre las basuras no resulta un caso aislado, pese a tratarse de un material potencialmente reutilizable con sólo volver a fundirlo, pues hay otros ejemplos donde abundan los desechos metálicos, como en el Castro de Yecla (González, 1945) y el Camino de los Afligidos (Fernández-Galiano, 1976b). La explicación que proponemos para el depósito de Vega Duero, que interpretamos como basurero, radica en que las gentes del lugar, no disponiendo de un taller donde pudiesen refundirse las piezas de hierro una vez que éstas se volvían inútiles, las abandonarían.

Del total de cerámicas destacan por su significación media docena de fragmentos de terra sigillata hispánica tardía de barniz anaranjado. Uno corresponde al borde de un plato y otro, decorado con motivos de grandes círculos, formaría parte de una Dragendorf 37 (fig. 4), mientras que el resto son inclasificables.

En el conjunto de la muestra cerámica se observa el predominio de las pastas grisáceas (posiblemente debido a una cocción reductora), con un porcentaje del $75,37 \%$, al tiempo que pastas rojizas sólo hacen acto de presencia en un 7,63\% y pastas mixtas en un $17 \%$. Los desgrasantes son por lo general medios y finos, de sílice y caliza, y las super- 


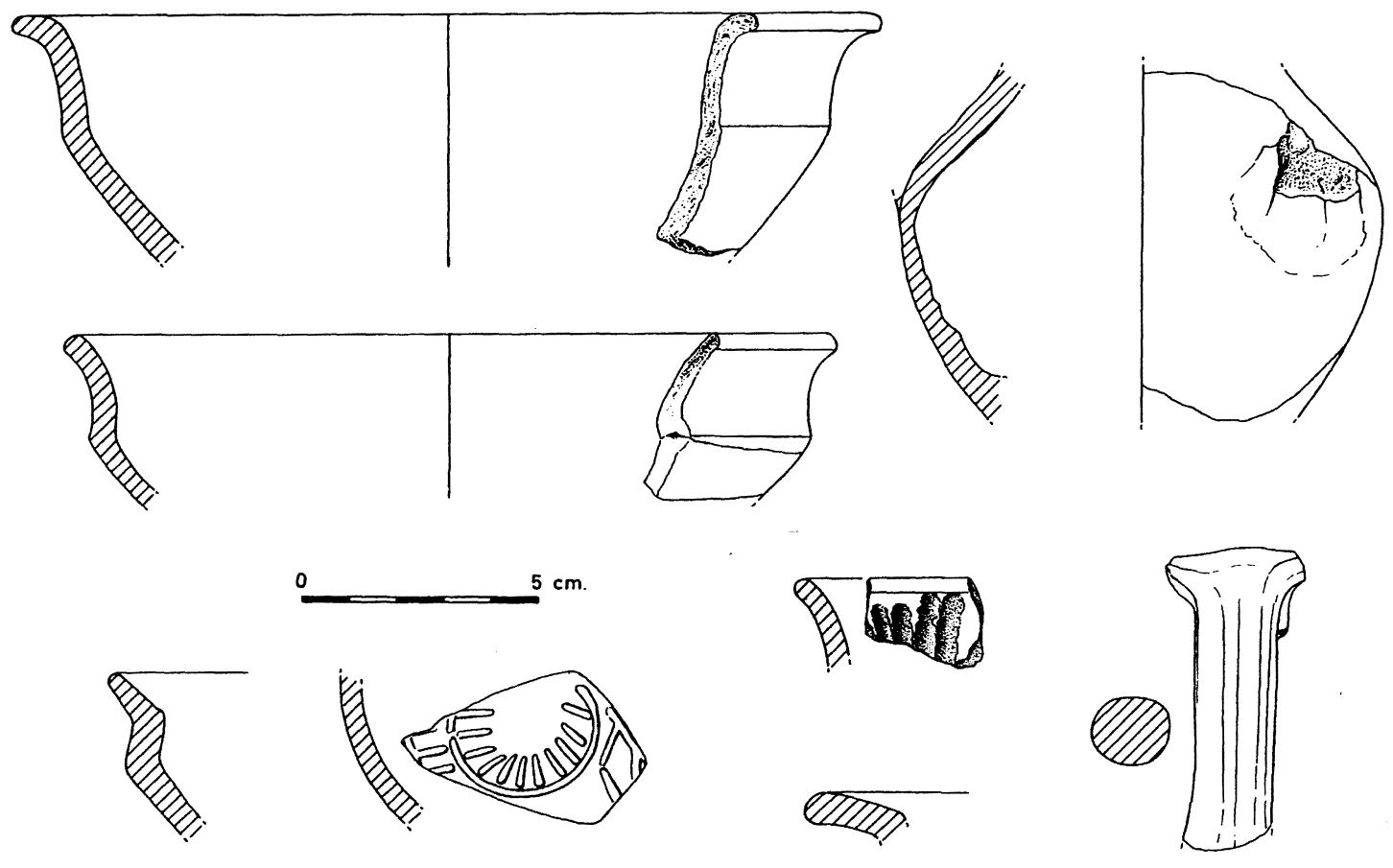

Fig. 4.-Materiales cerámicos: fragmento de terra sigillata, varios cuencos carenados y fragmentos de botellas. Escala $1 / 2$.

ficies muestran acabados toscos o alisados, aunque algunas piezas cuentan con finos bruñidos. Los bordes son en su mayoría vueltos, aunque no faltan otros exvasados, los fondos planos y las asas tienen secciones de cinta o cilíndricas.

Entre las formas cerámicas destaca en primer lugar el cuenco carenado (fig. 4). Sus paredes son ligeramente curvadas hacia fuera o rectas y la parte por encima de la carena es vertical, con paredes rectas o adoptando una curva hacia dentro. Aunque en un caso el labio es vuelto, el modelo más común posee labio exvasado, con lo que se incluiría en la forma B. 3 de Caballero. Sus superficies, pese a carecer de decoración, han sido finamente bruñidas, dándoles un aspecto brillante. La forma tiene un claro origen romano y vendría a constituir una simplificación de la Rig. 18; más concretamente deriva de las formas tardorromanas Rig. 22 y TSHt 11 de Palol y Cortés. Estos cuencos aparecen en algunos yacimientos tardorromanos, pero sobre todo en los de época visigoda del siglo V al VII (Caballero, 1989: 93-4; Larrén, 1989: 62).

Relacionadas con las anteriores por su fino acabado, se encontrarían las botellas (fig. 4). Pueden presentar asas y las superficies han sido espatuladas, llegando en un caso a adoptar este acabado una función decorativa mediante una disposición de bandas verticales bajo el borde. Varios fragmentos de asas, también espatuladas, pertenecerían a formas similares (fig. 4).

Otra forma frecuente es la olla (fig. 5). El cuerpo es globular y presenta variantes en la disposición de la boca. Unas pocas piezas muestran un cuello breve y sin marcar el labio o con éste vuelto, pero en general predominan las piezas que dibujan claramente el cuello y cuentan con labio exvasado. Estas últimas, y algunos framentos de forma indeterminable, muestran una decoración incisa en la zona de conexión entre el cuerpo y el cuello que consiste en bandas horizontales y onduladas efectuadas con peine o en una onda simple enmarcada por dos líneas horizontales.

A sendas orzas pertenecerían los dos fragmentos de vasijas con paredes reentrantes, sin cuello y labios vueltos, cuya parte superior se decora en una de las piezas con una ancha incisión meandriforme (fig. 5). Varios fragmentos recogidos en la excavación pertenecían a tres grandes recipientes de los que desconocemos la forma pero que resaltan por su tosco acabado y pastas ricas en desgrasantes micáceos y silíceos y cuya función guardaría relación con el fuego. El fondo de una vasija parece haberse reaprovechado como tapadera (fig. 5). Asimismo, además de las decoraciones incisas antes descritas, debemos mencionar que un pequeño fragmento de galbo contaba con un cordón plástico liso. 

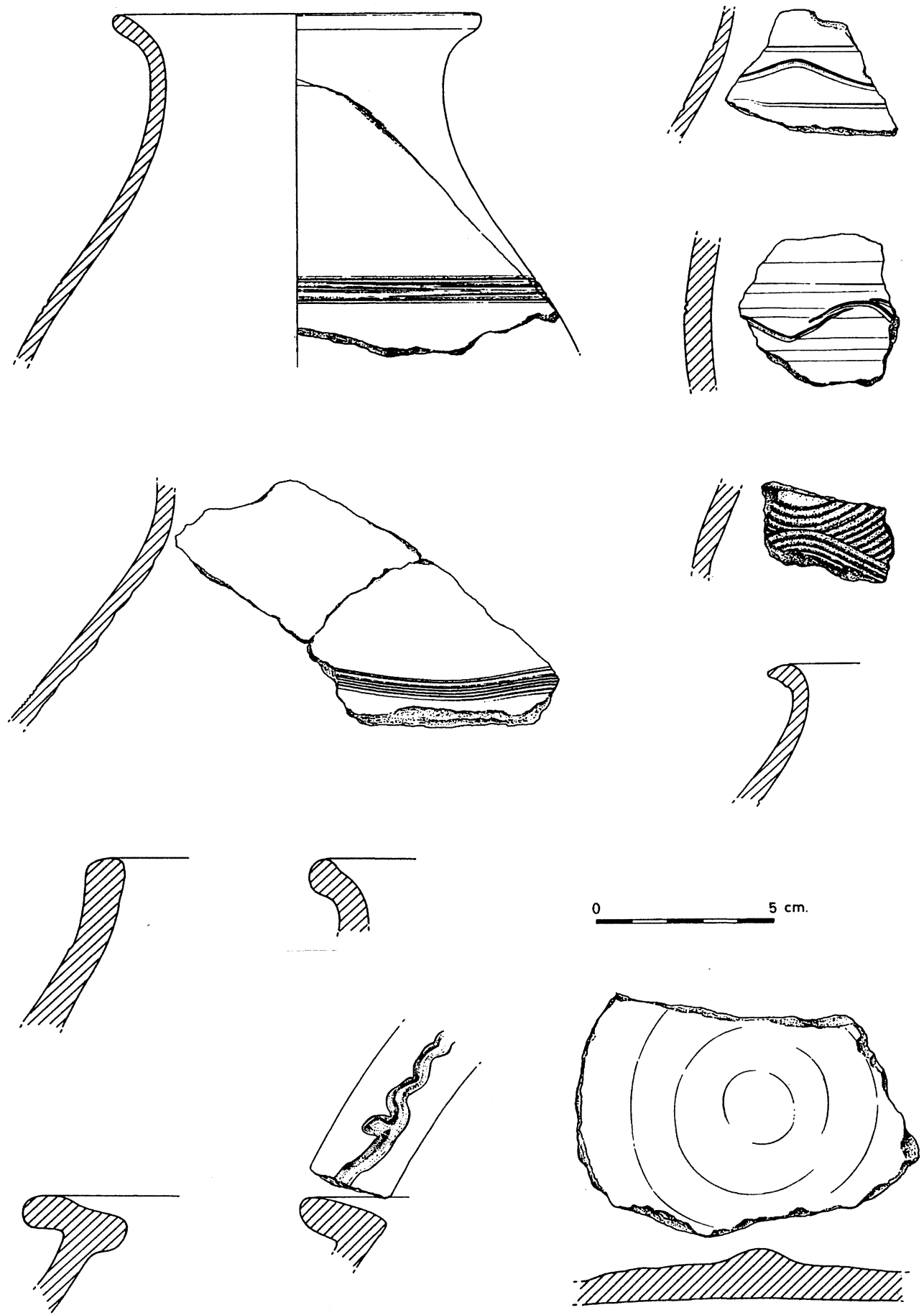

Fig. 5.-Materiales cerámicos: diversos fragmentos de ollas y orzas. Escala 1/2.

Para la cronología del yacimiento hemos de considerar el interés que supone la presencia de las sigillatas y las tijeras, materiales que se ligarían al mundo tardorromano y que se mantendrían durante el proceso de disolución de lo romano y los comienzos de la época visigoda, cronología a la que haríamos corresponder el yacimiento. La desaparición de la sigillata anaranjada se produciría en un momento im- 
preciso del siglo v (Caballero, 1989: 86), al tiempo que se aprecia cómo gana predicamento la cocción reductora, si bien esa sigillata perdura en exiguas muestras hasta el VI (Abásolo et alii, 1984: 171; Bohigas y Ruiz, 1989: 50). Por otro lado, si contemplamos los conjuntos cerámicos de algunos yacimientos datados a partir del siglo v, como los de Cañal (Fabián et alii, 1986) y Perales (Quero y Martín, 1987), se manifiesta la ausencia de cerámicas romanas. Estaríamos ante enclaves con materiales de tipología adscribible a la etapa visigoda donde ya se ha producido la desaparición de las antiguas sigillatas.

El grueso de la producción cerámica de Vega Duero coincide en líneas generales (parecidas formas y similares decoraciones colocadas en las mismas zonas de las vasijas) con otros yacimientos sincrónicos como los de Cañal en Salamanca (Fabián et alii, 1986: 192-3), Perales del Río en Madrid (Quero y Martín, 1987: 365-70), El Castelar de Doñajimena (Bohigas y Ruiz, 1987: 39-42) y el castro de Monte Cildá en Palencia (ibídem: 44-8) y Navasangil en Ávila (Larrén, 1989: 56 y 62-73). Faltan en Vega Duero algunos materiales característicos de este mundo, básicamente decoraciones impresas -bien digitaciones, bien estampillas-y pintadas; no obstante, esas faltas pueden deberse a lo limitado de la muestra que manejamos.

Sobre la datación, la única fecha de C-14 documentada en un yacimiento de esta época correspon-

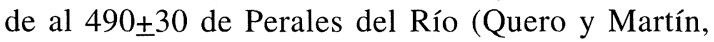
1987: 372) y, aunque una datación aislada no proporciona ninguna seguridad, habría que pensar que en torno a este momento ya existirían enclaves exclusivamente con materiales de tipología hispanovisigoda y donde se habría diluido lo tardorromano. El resto de los asentamientos que hemos mencionado se fecha de forma imprecisa entre los siglos $v$ y VII, aunque se trata de una apreciación difusa en torno al «periodo visigodo» que comenzaría bien entrado el siglo v y se extendería hasta el año 711 (Caballero, 1989: 86). Para Vega Duero, por la mezcla de evidencias de los dos mundos, creemos que el desarrollo del yacimiento se situaría en torno a la segunda mitad del siglo v, que habría sido aproximadamente el punto de inflexión en que conviven ambos grupos de producciones.

\section{CONSIDERACIONES SOBRE VEGA DUERO Y EL POBLAMIENTO DE ÉPOCA VISIGODA EN EL ÁREA}

Pese a que la excavación sólo ha proporcionado la identificación de estructuras subterráneas, nos encontramos sin duda ante un poblado, según puede deducirse de otros enclaves similares. En Perales del Río (Madrid), trabajos previos a la excavación arqueológica allí efectuada causaron la explanación del terreno, perdiéndose los niveles superiores hasta $80 \mathrm{~cm}$ de profundidad y, por tanto, todas las estructuras constructivas, hecho que determinó que sólo se localizaran las fosas subterráneas (Quero y Martín, 1987: 364). Asimismo, en el Camino de los Afligidos (Alcalá de Henares, Madrid) el propio carácter de urgencia de la intervención realizada impidió excavar alrededor de los hoyos - mismo problema al planteado en Vega Duero-, lo que imposibilitó la búsqueda de algún muro o estructura del asentamiento; no obstante, se afirma que las fosas habrían de pertenecer a dos habitaciones, probablemente cocinas, por la gran cantidad de huesos y cerámicas aparecidas (Fernández-Galiano, 1976b: 46). Para el caso de Torralba (Lorca, Murcia), el sector donde aparecen los silos se considera una aldea donde vivían los trabajadores de las tierras (Martínez y Matilla, 1988: 539).

Contamos además con el apreciable testimonio de una serie de estructuras visibles que se distribuyen en el cortado del río a lo largo de 160 metros. La mayoría corresponde a grandes fosas excavadas en el sustrato geológico del pago, cuya funcionalidad podría corresponder a silos o a vertederos y de las que no sabemos a priori si se situarían en lugares de habitación o en zonas de actividad o de paso. No obstante, otras, como algún muro de caliza y fosas de menor tamaño, se ligarían más probablemente a zonas de habitación. Los restos superficiales en el yacimiento no evidencian la posibilidad de que existan edificios de carácter monumental, más bien al contrario, pues aunque se encontraban numerosas piedras calizas, habían sido muy poco trabajadas y no tenían superficies escuadradas. La reducida dimensión del hábitat y el carácter de las estructuras excavadas son elementos que confirman la impresión de que nos encontramos ante un asentamiento campesino, probablemente de tipo aldea o granja.

El poblado se dispone, como ya hemos señalado, en la ribera del río Duero, en unas tierras especialmente aptas para la agricultura. No contamos con datos medioambientales que nos confirmen objetivamente este supuesto aprovechamiento agrícolaganadero, si bien la explotación que de este tipo de áreas se realizó desde las villas romanas (Fernández Castro, 1982: 24-5) induce a sospechar una continuidad. Un modelo de poblamiento en buena medida similar, aunque se ha descubierto una mayor cantidad de asentamientos, se documenta en el sureste 
de Salamanca. Se trata de una zona con emplazamientos dispuestos en el fondo del valle, sobre espacios abiertos que carecen de pretensiones defensivas y se orientan hacia una explotación agropecuaria (Fabián et alii, 1986: 198).

El yacimiento de Vega Duero está muy próximo, tan sólo dista 300 metros, al pago denominado El Convento, donde se ubica un establecimiento altoimperial y tardorromano en el que se han reconocido diversos restos constructivos: pisos de calicostre, ladrillos, ímbrices y tégulas (Mañanes, 1983: 74). Su existencia, que no parece alcanzar la etapa visigoda, bien pudiera guardar alguna relación con Vega Duero. Existiría una relación entre las ocupaciones de estos dos yacimientos, correspondiendo el más moderno a un abandono de las estancias nobles de la villa y la ocupación de una zona que con anterioridad era marginal. No sabemos si el paso de un lugar a otro fue inmediato o se produjo un hiato, que en cualquier caso no sería muy prolongado, durante el cual se produjo un abandono de Vega Duero. Lo que sí hemos constatado, dentro de la reducida área excavada, es la ausencia de restos que puedan adscribirse a la época del Convento dentro de Vega Duero y que permitan hablar por lo tanto de que ésta era un área con edificaciones de servicio de aquélla.

Hacia mediados del siglo v se produce un fenómeno generalizado en toda la península de abandono de las villas romanas. Parece haber existido un traslado de la población a nuevos emplazamientos, pero sin que lleguen a despoblarse las comarcas anteriormente habitadas pues, aunque se sabe poco de los hábitats, ahí están las necrópolis para testimoniar la presencia humana. Un proceso idéntico puede haberse producido en esta zona del valle del Duero (tenemos el ejemplo palentino de Monte Cildá, que tras haber sido abandonado en el siglo I, es reocupado ahora, en el v), afectando directamente al Convento y Vega Duero. Lo mismo ocurre en la cercana provincia de Soria donde, además de la tendencia a reocupar antiguos hábitats prerromanos en los rebordes montañosos, se aprecia un cierto paralelismo en la ocupación del espacio rural entre los asentamientos tardorromanos y los nuevos de época visigoda (Gómez Santa Cruz, 1992: 947). En las villae tardorromanas del área de Alcalá de Henares se ha constatado que no aparece ningún material posterior al siglo v o inicios del vi (Fernández-Galiano, 1976a: 110). El fenómeno se atestigua en la misma Complutum, que es abandonada en el primer tercio del siglo $\mathrm{v}$ en beneficio de un patrón espacial de ocupación más disperso, donde se sucederían casas, espacios cultivados y pastos (Méndez y Ras- cón, 1992: 96-8). También en el Sureste peninsular se constata una transformación del hábitat en los siglos v y VI, pues los materiales más modernos de las villae corresponden al siglo $\mathrm{v}$ y desde este momento la población tiende a deshabitarlas y concentrarse en lugares altos y de difícil acceso (Gutiérrez, 1988: 325 y Ruiz Molina, 1988: 580).

No conocemos en detalle los determinantes de un proceso de reorganización territorial de semejante índole. Pese a la falta de referencias a Hispania en las fuentes clásicas, gracias a la documentación arqueológica tenemos constancia de que se produjo un florecimiento y crecimiento de la economía hispana en el siglo IV (Palol, 1970). A partir del año 411 comienza el asentamiento de germanos en la península (citado por Hidacio, Isidoro y Orosio), pero es sobre todo a mediados del siglo cuando se intensifican las luchas y ya en el 441 la revuelta de los bagaudas se manifiesta en la Meseta. En 456 Teodorico II se introduce en el reino suevo y saquea con sus tropas Astorga y Braga -capital sueva-, siendo de nuevo saqueadas Palencia y Astorga al año siguiente. De nuevo entre 457 y 462 continúan las depredaciones entre suevos y godos, centradas básicamente en Tierra de Campos, que se prolongan hasta que en 470-475 Eurico se hace con el control de Hispania, aunque el fin de la inestabilidad no se asegura hasta 494-497 cuando, según la Chronica Caesaraugustana, Alarico II lleva a los primeros godos a establecerse en Hispania (Palol, 1970: 2530; Palol y Cortés, 1974: 206). La tensión pudo haber alterado el status romano tradicional y ser el origen de una nueva organización, causando modificaciones en la ocupación del territorio. No obstante, el momento final de la aristocracia rural y sus fundi se adecua más a las revueltas de colonos y esclavos que a la presencia de los primeros asentamientos godos; de cualquier modo, parece que se produjo una transformación en los sistemas de explotación y residencia señorial de estos grandes centros y que de ellos permaneció la parte rural y ganadera, abandonándose sólo la villa urbana o la parte más noble (Palol, 1987: 356). De hecho es poco probable que los asentamientos visigodos se superpongan a los fundi agrarios, pues son raros los elementos germánicos documentados arqueológicamente en ellos (ibídem: 358-9).

Falta, pese a todo, conocer con certeza la estructura del poblamiento. Se ha sugerido la existencia de tres tipos distintos de yacimientos hispanovisigodos (necrópolis asociadas a villas romanas, poblados en llano y asentamientos en castro) que se desarrollarían sucesivamente en el tiempo (Arranz et alii, 1989: 8). No obstante, consideramos más facti- 
ble que se trate de tres modelos de estaciones sincrónicas que, sumadas, forman un sistema coherente de ocupación del territorio, en el cual, en todo caso, sólo sería algo posterior la aparición de los castros. Habría de existir probablemente algún núcleo principal en un emplazamiento netamente defensivo similar a los del Sureste, dominando un área que contase con varios hábitat de carácter agropecuario y rural. Acerca de tales castros, Palol (1970: 19) señaló su coincidencia con puntos clave de las vías romanas y de los cauces fluviales. Al mismo tiempo algunos de los cementerios aprovecharían los muros de las antiguas villas cercanas a los nuevos núcleos de población. Se conformaría de este modo una ocupación como la del sureste de Salamanca, que aparece centrada en el asentamiento de Salvatierra de Tormes, donde se documentan incluso restos de carácter monumental (Fabián et alii, 1986: 188).

Lamentablemente, lo que hoy se sabe de la provincia de Valladolid en época visigoda está polarizado en sus necrópolis. Ya hace veinte años hablaba Palol del desconocimiento existente (Palol y Wattenberg, 1974: 52-4), que no ha venido a paliarse con posterioridad. De los once yacimientos conocidos en 1974 (ibídem: 229), tan sólo se ha pasado a veintitrés en 1989 -de los cuales ocho resultan simples hallazgos aislados-, en su mayoría necrópolis de las que, pese a la transcendencia que tendrían para localizar los hábitats (Ripoll, 1989: 390), se ignora la localización de sus poblados correspondientes (Arranz et alii, 1989: 8-9). Habrá de buscarse en el análisis de las villas romanas y su evolución la solución al cambio poblacional del siglo $\mathrm{v}$.

\section{BIBLIOGRAFÍA}

Abásolo, J. A., Cortés, J., Pérez, F. y Vighi, A., 1984: Excavaciones en el yacimiento de la Morterona, Saldaña (Palencia), Palencia.

Alonso Ponga, J. L., 1986: Huellas de Castilla y León. La arquitectura del barro, Valladolid.

Arranz Mínguez, J. A., Carretero Vaquero, S., Repiso Cobo, S. y San Miguel Maté, L. C., 1989: Arqueología hispanovisigoda en Valladolid. El yacimiento de Piñel de Abajo, Revista de Arqueología, $\mathrm{n}^{\circ} 104$, diciembre, 8-12.

Bohigas Roldán, R. y Ruiz Gutiérrez, A., 1989: Las cerámicas visigodas de poblado en Cantabria y Palencia, Boletín de Arqueología Medieval, 3, 31-51.

Borobia Melendo, E. L., 1988: Instrumental médico-quirúrgico en la Hispania romana, Madrid.
Burillo Mozota, F., 1983: El poblado de época ibérica y yacimiento medieval: «Los Castellares» (Herrera de los Navarros- Zaragoza) -I, Institución 'Fernando El Católico' (CSIC), Zaragoza.

Caballero Zoreda, L., 1974: La necrópolis tardorromana de Fuentespreadas (Zamora). Un asentamiento en el valle del Duero, Excavaciones Arqueológicas en España, 80.

Caballero Zoreda, L., 1985: Hallazgo de un conjunto tardorromano en la calle Sur de Getafe (Madrid), Boletín del Museo Arqueológico Nacional, III, 97-127.

Caballero Zoreda, L., 1989: Cerámicas de época visigoda y postvisigoda de la provincia de Cáceres, Madrid y Segovia, Boletín de Arqueología Medieval, 3, 75-107.

Colmenarejo García, F., 1986: El yacimiento arqueológico de Fuente del Moro, Actas del I Congreso de Arqueología Medieval Española (Huesca, abril de 1985), tomo II. Visigoda, Zaragoza, 221-239.

Fabián, J. F., Santonja Gómez, M., Fernández MoYANO, A. y BENET, N., 1986: Los poblados hispano-visigodos de 'Cañal', Pelayos (Salamanca). Consideraciones sobre el poblamiento entre los siglos V y VII en el SE de la provincia de Salamanca, Actas del I Congreso de Arqueología Medieval Española (Huesca, abril de 1985), tomo II. Visigoda, Zaragoza, 187-202.

Fernández CASTRO, M ${ }^{\mathrm{a}}$ C., 1982: Villas romanas en España, Madrid.

Fernández-Galiano Ruiz, D., 1976a: Carta Arqueológica de Alcalá de Henares y su partido, Colección Universitaria, 2, Alcalá de Henares.

Fernández-Galiano Ruiz, D., 1976b: Excavaciones en la necrópolis hispano-visigoda del Camino de los Afligidos (Alcalá de Henares), Noticiario Arqueológico Hispánico, 4, Arqueología, 5-90.

Gómez Santa CRUZ, J., 1992: Aproximación al poblamiento hispano-romano en la provincia de Soria, Actas del $2^{\circ}$ Symposium de Arqueología Soriana (octubre de 1989), vol. II, Soria, 937-56.

González Salas, S., 1945: El Castro de Yecla, en Santo Domingo de Silos (Burgos), Informes y Memorias, $\mathrm{n}^{\circ} 7$.

GutiérRez Lloret, S., 1988: El poblamiento tardorromano en Alicante a través de los testimonios materiales: estado de la cuestión y perspectivas, Arte y poblamiento en el SE peninsular durante los últimos siglos de la civilización romana, Antigüedad y Cristianismo. Monografías históricas sobre la antigüedad tardía $\mathrm{V}$, Universidad de Murcia, 323-37.

Josué Simonena, C., 1988: Poblamiento rural de 
Navarra en la Edad Media. Bases arqueológicas. Valle de Urraul Bajo, Pamplona.

LARRÉn IzQUiERDO, H., 1989: Materiales cerámicos de la Cabeza-Navasangil (Ávila), Boletín de Arqueología Medieval, 3, 53-74.

Larrén IzQuierdo, H., 1990: San Miguel de Escalada: Trabajos arqueológicos 1983-1987, Numantia. Investigaciones arqueológicas en Castilla y León, III, 217-238.

Manning, W. H., 1989: Catalogue of the RomanoBritish Iron Tools, Fittings and Weapons in the British Museum, British Museum Publications, London ( $2^{\mathrm{a}}$ impresión).

Mañanes PÉRez, T., 1983: Arqueología vallisoletana. II. Torozos, Pisuerga y Cerrato, Valladolid.

Martínez Rodríguez, A. y Matilla Seiquer, G., 1988: Poblamiento tardío en Torralba, Lorca, Arte y poblamiento en el SE peninsular durante los últimos siglos de la civilización romana, Antigüedad y Cristianismo. Monografías históricas sobre la antigüedad tardía V, Universidad de Murcia, 503-41.

Méndez Madariaga, A. y Rascón Marqués, S., 1992: 'Complutum' y el bajo Henares en época visigoda, III Congreso de Arqueología Medieval Española (Oviedo, 27 marzo-1 abril 1989), Actas, II. Comunicaciones, Universidad de Oviedo, 96-102.

Palol, P. de, 1964: Cuchillo hispanorromano del siglo Iv de J. C., Boletín del Seminario de Estudios de Arte y Arqueología, XXX, 67-102.

PAlol, P. de, 1969: La necrópolis de San Miguel del Arroyo y los broches hispanorromanos del siglo Iv, Boletín del Seminario de Estudios de Arte y Arqueología, XXXIV-XXXV, 93-160.

Palol, P. de, 1970: Castilla la Vieja entre el Imperio Romano y el Reino Visigodo, Lección inaugu- ral del curso 1970-71 de la Universidad de Valladolid, Valladolid.

Palol, P. de, 1987: Palencia al final del mundo antiguo, Actas del I Congreso de Historia de Palencia (Monzón de Campos, diciembre de 1985), tomo I, 345-59.

PAlOL, P. de y CoRTÉs, J., 1974: La villa romana de La Olmeda, Pedrosa de la Vega (Palencia). Excavaciones de 1969 y 1970, Acta Arqueológica Hispánica, VII.

Palol, P. de y Wattenberg, F., 1974: Carta Arqueológica de España. Valladolid, Valladolid.

Quero Castro, S. y Martín Flores, A., 1987: La cerámica hispanovisigoda de Perales, II Congreso de Arqueología Medieval Española (Madrid, 19-24 enero 1987), Actas, II. Comunicaciones, Madrid, 363-72.

Ripoll LóPEZ, G., 1985: La necrópolis visigoda de El Carpio de Tajo (Toledo), Excavaciones Arqueológicas en España, 142.

RIPOLl LÓPEZ, G., 1989: Características generales del poblamiento y la arqueología funeraria visigoda de Hispania, Espacio, Tiempo y Forma, serie I, Prehistoria y Arqueología, 2, 389-418.

Ripoll LóPEZ, G., 1993-1994: La necrópolis visigoda de El Carpio de Tajo. Una nueva lectura a partir de la topocronología y los adornos personales, Butlletí de la Reial Académia Catalana de Belles Arts de Sant Jordi, VII-VIII, 187-250.

Ruiz Molina, L., 1988: El poblamiento romano en el área de Yecla (Murcia), Arte y poblamiento en el SE peninsular durante los últimos siglos de la civilización romana, Antigüedad y Cristianismo. Monografías históricas sobre la antigüedad tardía V, Universidad de Murcia, 565-98.

Zeiss, H., 1934: Die Grabfunde aus dem Spanischen Westgotenreich, Berlin und Leipzig. 